\title{
Glucose-6-phosphate dehydrogenase status and neonatal jaundice
}

\author{
K L TAN \\ Department of Paediatrics (Neonatal Unit), University of Singapore
}

SUMMARY Neonatal jaundice and its relationship to glucose-6-phosphate dehydrogenase (G6PD) status of healthy, term Chinese infants was evaluated in 220 G6PD-deficient infants, 26 intermediate infants who were observed for 3 weeks, and 116 normal (control) infants. Each infant was free of isoimmunisation, cephalhaematomas, or contusions. The mode of labour, method of delivery, and type of feeds had no appreciable effect on daily bilirubin levels. 'Elevated' physiological jaundice was associated with normal and G6PD-intermediate status; there was no increased haemolysis. G6PD-deficient status was associated with jaundice significantly raised especially in the first week of life, and prolonged beyond that of the 'elevated' physiological jaundice. Significantly increased though mild haemolysis was observed. Close surveillance is therefore required for G6PD-deficient infants at least for the first week of life, the period of increased risk. With G6PD-intermediate infants, only the usual measures for normal infants are required.

Neonatal jaundice is common in newborn infants in Singapore, especially in Chinese infants; ${ }^{\mathbf{1}}$ at least $5 \%$ of term Chinese infants suffer from hyperbilirubinaemia (bilirubin level $>15 \mathrm{mg} / 100 \mathrm{ml}$ or $255 \mu \mathrm{mol} / \mathrm{l}) .^{2}$ The incidence of hyperbilirubinaemia in glucose-6-phosphate dehydrogenase- (G6PD) deficient infants is even higher. ${ }^{3}$ The jaundice in such infants is also more prolonged.

The increased incidence and severity of neonatal jaundice in G6PD-deficient infants, often causing kernicterus in the past, have been partly ascribed to the cultural practices of the local Chinese in the care of newborn infants which in some cases have used agents potentially haemolytic for G6PD-deficient red cells. ${ }^{3}$ However, with better education and dissemination of knowledge, such practices have declined to negligible levels. It was therefore thought that a re-evaluation of neonatal jaundice in relation to the G6PD status of infants would be timely. The present paper is the result of such a study.

\section{Methods and materials}

In the Kandang Kerbau Hospital, Singapore, routine screening of all cord bloods for G6PD deficiency using a modification of Bernstein's method $^{3}$ is practised. G6PD deficiency is transmitted by a sex-linked gene of intermediate dominance, with full expression only occurring in hemizygous males and homozygous females, and intermediate expression in heterozygous females. All infants found to be G6PD-deficient or intermediate are routinely observed as inpatients for 3 weeks.

The present investigation was performed on alf healthy, term G6PD-deficient or intermediate Chinese infants delivered in the hospital during 1979\% Blood from each mother and infant was taken for grouping and antibody studies. Only infants of healthy mothers with no evidence of isoimmunisation, contusions, or cephalhaematomas were included in this study. A separate group, randomly selected, of healthy, term G6PD normal Chinese infants, normally delivered and with no isoimmunisation, contusions, or cephalhaematomas served as controls. For obvious reasons, they were discharged after 5 days, unless a rising bilirubin trend or any other contraindication was present. Informed consent was obtained.

All the infants were routinely swaddled with only the face exposed, and nursed in open cots in the nursery. The illumination in the nursery averaged 43 lux and the energy output 2.5 microwatts $/ \mathrm{cm}^{2}$ $\left(\mu \mathrm{W} / \mathrm{cm}^{2}\right)$ in the 425 to 475 nanometer $(\mathrm{nm})$ range and $4.0 \mu \mathrm{W} / \mathrm{cm}^{2}$ in the 400 to $500 \mathrm{~nm}$ range. The measurements were made by the $11 \mathrm{~A}$ Photometer/ Radiometer/United Detector Technology Inc, USA.

Bilirubin levels were monitored daily in the morning for the first 8 days after delivery, and thereafter on the 10th, 14th, and 21st days of life. The haemoglobin $(\mathrm{Hb})$ values were determined on the 1st, 8th, 14th, and 21 st days of life. The control infants however, could be monitored for only 5 days. 
Any infant developing hyperbilirubinaemia during this period was given phototherapy and excluded from the study group from the start of treatment.

Capillary blood samples for bilirubin estimation were kept away from light in a light-tight box until the moment of bilirubin determination. All samples were determined in the same laboratory under identical conditions. The bilirubin levels were determined by the AO Bilirubinometer (American Optical Corporation, USA). The results obtained by this method were comparable with those by the method of Malloy and Evelyn. ${ }^{4}$ Direct acting bilirubin was determined in random samples by the method of Malloy and Evelyn.

The results were subjected to statistical evaluation.

\section{Results}

Three hundred and sixty-two neonates were studied (Table). Two hundred and two of the G6PD-deficient infants had been delivered normally, 128 were the result of spontaneous labours, 49 from amniotomy and oxytocin induction, and 25 from spontaneous labours augmented by oxytocin. Twelve infants had been delivered by forceps, 8 by outlet forceps; 3 of the cases had been from amniotomy and oxytocininduced labours, the rest from spontaneous labours. Five neonates were delivered by caesarean section of which only one was elective, the other 4 being emergency sections for fetal distress $(n=2)$ and obstruction $(n=2)$ during spontaneous labours. One neonate was delivered by the breech from a spontaneous labour. Of the G6PD intermediate infants, only one was delivered by elective caesarean section, the rest normally, 6 from amniotomy and oxytocin-induced labours, and the remaining 19 from spontaneous labours. One-quarter of the 116
G6PD normal controls were delivered as a result of amniotomy and oxytocin-induced labours, and the rest from spontaneous labours. Anaesthesia for caesarean section consisted routinely of thiopentone, nitrous oxide, and curare.

All the infants were in satisfactory condition immediately after delivery. Feeds were begun at about 6 hours of age. All the G6PD-deficient and intermediate infants were formula-fed except for 5 (4 in the deficient group) who were breast fed. Of the normal infants only 10 were breast fed.

In the G6PD-deficient group of infants, the bilirubin levels of those delivered from amniotomy and oxytocin-induced labours were not appreciably different from those delivered from spontaneous labours or from spontaneous labours augmented by oxytocin; similar findings were observed with the group of infants delivered by assisted or operative methods when compared with those delivered normally either spontaneously or otherwise. The findings were the same in the G6PD intermediate and normal groups of infants. In the G6PD normal group, the bilirubin levels of the breast-fed infants were again observed to be not significantly different from those of the formula-fed infants. The numbers of infants in the G6PD-deficient or intermediate groups who were breast fed were too few for any valid observations on bilirubin levels to be made; the bilirubin levels of the 5 infants were however within the range of the formula-fed infants. No sex difference in bilirubin values was observed in the G6PD normal infants. It was therefore deemed valid to use the daily mean bilirubin values of all the infants within each individual group regardless of mode of labour, method of delivery, type of feeds, and gender, in the evaluation of neonatal jaundice in relation to the G6PD status of infants.

Table Data of the infants studied

\begin{tabular}{|c|c|c|c|c|}
\hline & & $G 6 P D$-deficient group & $\begin{array}{l}\text { G6PD-intermediate } \\
\text { group }\end{array}$ & Normal group \\
\hline \multicolumn{2}{|l|}{ Number (M:F) } & $220: 0$ & $0: 26$ & $54: 62$ \\
\hline Birthweight (g) & $\begin{array}{l}\text { Mean } \\
\text { SE }\end{array}$ & $\begin{array}{c}3151 \\
28\end{array}$ & $\begin{array}{c}3070 \\
70\end{array}$ & $\begin{array}{r}3190 \\
39\end{array}$ \\
\hline Gestation (weeks) & $\begin{array}{l}\text { Mean } \\
\text { SE }\end{array}$ & $\begin{array}{l}39 \cdot 3 \\
0.07\end{array}$ & $\begin{array}{r}39 \cdot 1 \\
0 \cdot 2\end{array}$ & $\begin{array}{r}40 \cdot \overline{1} \\
0 \cdot 1\end{array}$ \\
\hline \multicolumn{5}{|l|}{$\mathrm{Hb}(\mathrm{g} / \mathrm{dl})$} \\
\hline 1 st day & $\begin{array}{l}\text { Mean } \\
\text { SE }\end{array}$ & $\begin{array}{c}18 \cdot 05^{*} \\
0.20\end{array}$ & $\begin{array}{r}18 \cdot 96 \\
0.38\end{array}$ & $\begin{array}{c}18 \cdot 81^{*} \\
0.27\end{array}$ \\
\hline 8 th day & $\begin{array}{l}\text { Mean } \\
\text { SE }\end{array}$ & $\begin{array}{r}15 \cdot 61 \\
0 \cdot 14\end{array}$ & $\begin{array}{r}16 \cdot 22 \\
0 \cdot 27\end{array}$ & - \\
\hline 14 th day & $\begin{array}{l}\text { Mean } \\
\text { SE }\end{array}$ & $\begin{array}{r}14 \cdot 27 \\
0 \cdot 14\end{array}$ & $\begin{array}{r}15.09 \\
0.36\end{array}$ & - \\
\hline 21 st day & $\begin{array}{l}\text { Mean } \\
\text { SE }\end{array}$ & $\begin{array}{c}12 \cdot 55 \ddagger \\
0 \cdot 14\end{array}$ & $\begin{array}{c}13 \cdot 85 \ddagger \\
0 \cdot 31\end{array}$ & - \\
\hline $\begin{array}{l}\text { Plasma bilirubin } \mathrm{m} \\
1 \text { st day }\end{array}$ & $\begin{array}{l}\text { Mean } \\
\text { SE }\end{array}$ & $\begin{array}{l}7 \cdot 1 \dagger^{* *}(121 \cdot 4) \\
0 \cdot 2(3 \cdot 4)\end{array}$ & $\begin{array}{l}5 \cdot 6^{* *}(97 \cdot 7) \\
0 \cdot 8(13 \cdot 7)\end{array}$ & $\begin{array}{l}2 \cdot 8 \dagger(47 \cdot 9) \\
0 \cdot 1(1 \cdot 7)\end{array}$ \\
\hline
\end{tabular}

Conversion: traditional to SI units-bilirubin $1 \mathrm{mg} / 100 \mathrm{ml} \approx 17 \cdot 1 \mu \mathrm{mol} / 1$

$* \mathrm{P}<0.05 \quad+\mathrm{P}<0.01 \quad+\mathrm{P}<0.001 \quad * * \mathrm{P}<0.02$ 
The 1st day bilirubin level of the G6PD-deficient group of infants was already significantly higher than that of the G6PD intermediate or normal group. The 1st day bilirubin level of the G6PD intermediate group was also significantly higher than that of the control group (Table). The bilirubin levels rose steadily until the 4th day when peak values were reached in all three groups (Figure). The rate of bilirubin rise in the control group was initially rapid resulting in its bilirubin level rising beyond that of the G6PD intermediate group by the 3rd day of life. The bilirubin values of the G6PD-deficient group however, remained significantly higher than those of the normal group throughout the first 5 days of life $(\mathrm{P}<0.001$ for the first 4 days, $\mathrm{P}<0.02$ for the 5 th day). There was also a significant difference in bilirubin values between the G6PD-deficient and intermediate groups from the 1st to 14th day of life at which time the bilirubin level of the G6PDdeficient group had declined to $3.9 \mathrm{mg} / 100 \mathrm{ml}$ $(67 \mu \mathrm{mol} / \mathrm{l})$, a value already reached by the G6PD intermediate group on the 8th day of life. The bilirubin level had declined so much in both groups by the $21 \mathrm{st}$ day of life that there was very little difference between the values of the two groups $(0.9>P>0.8)$.

In the G6PD-deficient group, 48 of the 220 infants developed hyperbilirubinaemia compared with 12 of the 116 normal infants, a difference that was significant $(P<0 \cdot 02)$. The incidence of hyperbilirubinaemia in the G6PD intermediate group, 2 of the 26 infants, was however not significantly different from that of the G6PD-deficient group (0.1 > $P>0.05)$ or the control group $(0.7>P>0 \cdot 6)$.

The direct acting bilirubin did not exceed 1 $\mathrm{mg} / 100 \mathrm{ml}(17 \mu \mathrm{mol} / \mathrm{l})$ in any of the random samples determined.

The 1st day $\mathrm{Hb}$ value of the G6PD-deficient group was the lowest of the three groups. It was

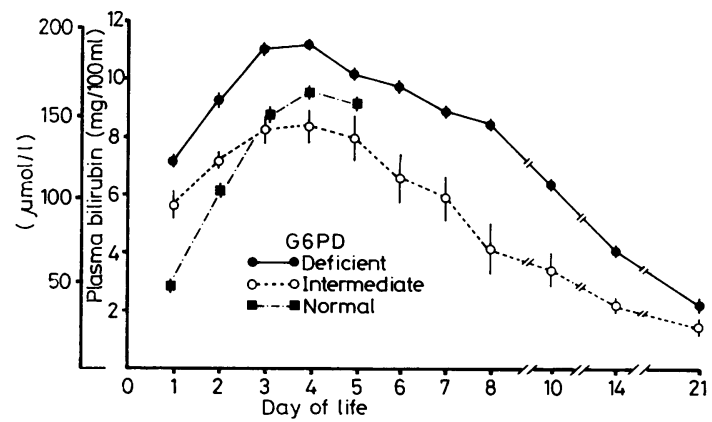

Figure Bilirubin levels of G6PD-deficient, intermediate, and normal infants. significantly lower than that of the normal group. Though the $\mathrm{Hb}$ level was initially not significantly lower than that of the G6PD intermediate group, the difference gradually increased becoming significant on the 21 st day of life (Table).

\section{Discussion}

The present study is believed to be the first to document bilirubin values under standard conditions in G6PD-deficient and intermediate infants continuously for the first 3 weeks of life. It demonstrates that even in a hospital environment free from agents potentially haemolytic to G6PD-deficient cells, the bilirubin levels of G6PD-deficient Chinese infants were still significantly higher than those of G6PD intermediate or normal infants. Furthermore, the incidence of hyperbilirubinaemia in G6PD-deficient infants $(22 \%)$ was more than twice that of normal infants $(9.5 \%)$, and thrice that of G6PD intermediate infants $(7 \cdot 7 \%)$ though in the last group the numbers were probably too few for the comparison to be significant. Had the infants with hyperbilirubinaemia been allowed to continue in the study group with no treatment, the bilirubin levels of the G6PD-deficient group would have been expected to be even higher, as observed in a previous studyk where exchange transfusion was resorted to only at a much higher bilirubin level.

The jaundice of G6PD-deficient infants als tended to be more prolonged, the value at the end of the second week of life being comparable with that of G6PD intermediate infants at the end of the first week of life. However, unlike a previous study, ${ }^{3}$ hyperbilirubinaemia only occurred within the first week of life in all cases regardless of G6PD status under the controlled conditions of this study. Nor did mode of labour, method of delivery, manner of feeds, or sex ratio apparently have any significant effect on the daily bilirubin values.

In the group of G6PD normal control infants, the bilirubin levels were comparable with those of a previous study ${ }^{1}$ made at a time when cultural practices were still fairly common in Singapore. The decline in such practices apparently had no effect on the bilirubin levels of normal healthy infants. This marked 'physiological' jaundice in the apparent absence of increased haemolysis suggests an underlying hepatic mechanism. It appears to be an ethnic characteristic of Chinese infants.

Although the initial bilirubin level of the G6PDintermediate group of infants was higher than that of the control group, it had fallen below that of the control group by the 3 rd day of life. From the trend of the bilirubin levels in the two groups, it is likely that the subsequent course of the bilirubin values of

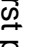
每 (a)

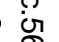

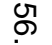
$\vec{\omega}$ $\underset{n}{\infty}$

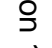
Z

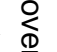

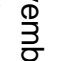
. $\overrightarrow{0}$ 黑 3 , 윽 음

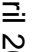
N 
the G6PD-intermediate group would either be similar or lower than those of the control group. The 1st day $\mathrm{Hb}$ levels of the two groups were similar and within the normal range for healthy infants; the subsequent $\mathrm{Hb}$ values of the G6PD-intermediate group on the 8th, 14th, and 21st days of life were also within the normal range of healthy term infants, ${ }^{5}$ indicating no increased haemolysis in this group. This study however, documents the association of the G6PD-intermediate status with an appreciable level of jaundice which also tends to be prolonged.

The underlying mechanism for this tendency towards severe and prolonged jaundice in G6PDdeficient infants appears to be a slightly increased rate of haemolysis during the first 3 weeks of life, which had apparently occurred in the absence of haemolytic agents. This slightly increased continued haemolysis superimposed on the increased physiological jaundice of Chinese infants could account for the severe and prolonged nature of the jaundice in G6PD-deficient infants.

The present study confirms a previous one in the same hospital ${ }^{6}$ demonstrating no association between oxytocin stimulation of labour and neonatal jaundice. Breast feeding was also demonstrated not to be associated with increased bilirubin levels though the numbers breast fed were too few to be conclusive. The role of these two factors in influencing bilirubin values in this study is therefore negligible.

The G6PD-deficient status is therefore associated with a much greater risk of severe and prolonged jaundice, even in the absence of potentially haemolytic agents. However, under controlled conditions, hyperbilirubinaemia either occurred within the first week of life, or not at all. It might therefore be feasible to discharge infants without hyperbilirubinaemia, after the first week of life, with careful instructions. The G6PD intermediate status however, is not associated with any such increased risk; therefore only the usual measures for G6PD normal infants need be taken.

I thank Professor H B Wong for encouragement, Dr K C Ng, Medical Superintendent, Kandang Kerbau Hospital, for permission to mount this study, P Mathavan and his laboratory staff for invaluable assistance, the nursing staff for enthusiastic help, Mrs L H Ow and J Tan for secretarial assistance.

\section{References}

1 Brown W R, Wong $\mathbf{H}$ B. Ethnic group differences in plasma bilirubin levels of full-term, healthy Singapore newborns. Pediatrics $1965 ; 36$ : 745-51.

2 Tan K L. Some aspects on management of neonatal jaundice in Singapore. J Singapore Paediatr Soc 1978; 20: 122-41.

${ }^{3}$ Brown W R, Wong $H$ B. Hyperbilirubinemia and kernicterus in glucose-6-phosphate dehydrogenasedeficient infants in Singapore. Pediatrics 1968; 41: 1055-62.

4 Malloy H T, Evelyn K A. The determination of bilirubin with the photoelectric colorimeter.J Biol Chem 1937; 119: 481-90.

5 Matoth Y, Zaizov R, Varsano I. Postnatal changes in some red cells parameters. Acta Paediatr Scand 1971 ; 60: 317-23.

6 Sivasuriya M, Tan K L, Salmon Y M, Karim S M M. Neonatal serum bilirubin levels in spontaneous and induced labour. Br J Obstet Gynaecol 1978; 85 : 619-23.

Correspondence to Professor K L Tan, Neonatal Unit, Kandang Kerbau Hospital, Singapore 0821.

Received 4 November 1980 